\title{
On the division of labor between roots and functional structure
}

\author{
Artemis Alexiadou \& Terje Lohndal \\ Humboldt University of Berlin \& Norwegian University of Science and Technology
}

\section{$1 \quad$ Introduction ${ }^{1}$}

Frameworks such as Distributed Morphology assume that the lexicon consists of roots and morphosyntactic features and that these roots are categorized by functional elements (Marantz 1997, Embick and Marantz 2008, Embick 2010). ${ }^{2}$ An example is provided in (1) where the root is either categorized as a verb (1a) or as a noun (1b).
a. $[\mathrm{v} v \sqrt{\mathrm{ROOT}}]$
b. $[\mathrm{n} n \sqrt{\mathrm{ROOT}}]$

The leading idea is that word formation is syntactic and that there are atomic, nondecomposable elements that are called roots. Importantly, in this theory, roots are category neutral. They enter the syntactic derivation without a category and are only categorized by combining with category-defining functional heads/labels.

\footnotetext{
${ }^{1}$ We are grateful to the audience at the Little $v$ conference in Leiden, the participants in the Research Seminar at the University of Stuttgart, and the members of the EXOGRAM research group in Trondheim, and Hans Petter Helland for valuable feedback on this paper. We also thank the anonymous reviewers for their helpful and thorough comments on a previous version.

${ }^{2}$ This assumption is also shared by exoskeletal approaches in general, that is, approaches capitalizing on the importance of structure as opposed to the properties of lexical items (Åfarli 2007, Ramchand 2008, this volume, Lohndal 2014, Alexiadou, Anagnostopoulou and Schäfer 2015). Roots are also adopted in Borer (2005a, b, 2013), although Borer explicitly rejects the assumption that roots are categorized. See also Pesetsky (1995).
} 
In this paper, we will discuss whether roots have independent meaning of their own. That is, do roots have substantial meaning independently of their syntactic configuration? This will lead us to consider whether or not roots are similar across languages, and our conclusion, following Arad (2003), will be negative. Instead, building on Arad (2003) and Anagnostopoulou \& Samioti (2014), we will propose a typology of languages based on the division of labor between little $\mathrm{v}$ and roots. In brief, some languages have highly general roots that can appear with a range of different meanings, whereas other languages have roots with severely restricted meanings.

The paper is structured as follows. Section 2 is a background section that discusses roots and categorizers more generally. Section 3 discusses roots in Hebrew and English, two languages that are quite different in terms of how much information each root encodes. Data from the history of English are reviewed in section 4, demonstrating that English used to make more use of overt verbalizing morphology in previous stages. Section 5 is an extensive discussion of roots in Greek, arguing that Greek is somewhere in between English and Hebrew. Our proposed typology is introduced in section 6 , and we present two different ways of capturing the typology. Concluding remarks are made in section 7.

\section{Background: Roots and categorizers}

Since Chomsky (1957), the interplay between syntax and morphology has been at the forefront of formal approaches to language. It has generated a lot of work and different hypotheses about the relationship between the two components (see e.g. Carstairs-McCarthy's 1992 overview, the contributions to Spencer \& Zwicky 1998, Hippilsey and Stump 2014, and the discussion in Baker 1985, Ackema and Neeleman 
2004, Borer 2005a, b, 2013, Di Sciullo 2005, Embick 2010, Julien 2002, and Caha 2009). There are many reasons why the syntax-morphology interface is an important issue in linguistic theory. First, there is the fundamental issue of whether syntactic operations are defined over 'words' or over smaller units (morphemes, morphs, roots, etc.). Second, and related to the first question, to what extent do functional syntactic structures encode morphological units? Importantly, exploring these two related issues will yield crucial insights into the architecture of the grammar, as can be seen from the widely different answers that have been provided in the literature (Aronoff 1976, Anderson 1992, Lieber 1992, Halle and Marantz 1993, Wunderlich 1996). Third, there is the question of possible differences between various kinds of morphological operations regarding whether they take place in the lexicon or in the syntax (e.g., famously derivational versus inflectional morphology, as in Chomsky 1970, Anderson 1982, Marantz 1997, Borer 2005a, b, 2013).

Distributed Morphology (henceforth, DM) argues in favor of what has become known as the 'single engine hypothesis' (Halle and Marantz 1993, Marantz 1997), which holds that all computation, be it small or big, is syntactic. Thus word formation is syntactic; operations within a lexicon are not permitted. On this view, the lexicon is assumed to consist of roots and functional heads such as categorizers. A root does not carry a category; it receives a category by being embedded in a structure which contains a categorizer. The three standard lexical categories are thus analyzed as in (2).

a.

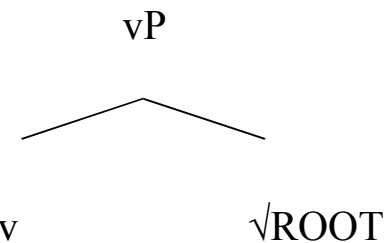

b. $n P$ 
c.

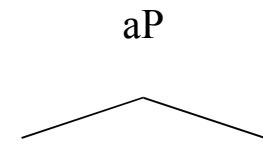

a

$\sqrt{ }$ ROOT

A given root can in theory appear in all environments, though in practice this does not happen all that often. Theorists thus often postulate constraints on roots in order to capture some of the restrictions that they appear to observe (see Harley 2014 for a review).

Languages differ in terms of whether the categorizer has an overt exponent. In English, this morphology is often not present. The following examples illustrate this for a few noun-verb pairs, though this is very common (Borer 2013 and references therein).

(3) a. a file - to file

b. a shop - to shop

c. a fish - to fish

d. a run - to run

However, the morphology can also be overt, as in the following examples.

(4) a. employ-employment

b. advertise - advertisement

(5) a. character - characterize

b. alphabet - alphabetize 
Other languages are different. In Hebrew, word-creating morphology is mostly overt and can easily be distinguished from the root. ${ }^{3}$ Roots in Hebrew mostly consist of segmental consonants, such as $\sqrt{ }$ CCC. As we will return to in section 3 , these roots do not have a fixed meaning. Pattern morphology is required in order to make the roots pronounceable. Considering verbs, there are seven possible patterns, and they are illustrated in (6) (Arad 2003: 742; see also Berman 1978, Doron 1999).

$(6)$

\begin{tabular}{|c|c|c|c|}
\hline Root: & Pattern (Binyan) & Verb: & \\
\hline Gmd & $1 \mathrm{CaCaC}$ & Gamad & 'be standing' \\
\hline Gmd & $2 \mathrm{niCCaC}$ & neYemad & 'stand up' \\
\hline qpl & $3 \mathrm{CiCCeC}$ & qipel & 'fold' - transitive \\
\hline qpl & $4 \mathrm{CuCCaC}$ & qupal & 'passive of 3 ' \\
\hline $\mathrm{md}$ & $5 \mathrm{hiCCiC}$ & heYemid & 'make stand up' \\
\hline Smd & $6 \mathrm{huCCaC}$ & huৎamad & 'passive of 5 ' \\
\hline qpl & 7 hitCaCCeC & hitqapel & 'fold' - intransitive \\
\hline
\end{tabular}

As these examples illustrate, the categorizers in Hebrew are crucially overt.

A core question concerns the content of a root. Are roots simply proxies that can appear in a given syntactic configuration or do they actually contribute some semantic content on their own? If they contribute meaning, can roots be catalogued into different baskets depending on their meaning?

\footnotetext{
${ }^{3}$ What follows about Hebrew is based on Arad (2003).
} 
In an influential paper, Harley (2005) suggests precisely this latter alternative. Her proposal is that roots can be divided into three categories: Things, Events, and States. We will briefly consider each of these three categories. ${ }^{4}$

Roots that denote Things are roots such as $\sqrt{ }$ FOAL and $\sqrt{ }$ DROOL (Harley 2005: 47). These roots are underlying direct objects, incorporating into the transitive verb and measuring out the event of the root
a. The mare foaled
\#for two hours/in two hours.
b. The mare bore a foal
\#for two hours/in two hours.
a. The baby drooled
for two hours/\#in two hours.
b. The baby made drool
for two hours/\#in two hours.

(8)

A root such as $\sqrt{ }$ FOAL yields a bounded telic predicate, measured out by the root. Roots such as $\sqrt{ }$ DROOL on the other hand yield an unbounded atelic predicate.

Roots denoting Things behave differently from roots that denote Events, such as $\sqrt{ } \mathrm{HOP}$ and $\sqrt{\mathrm{DANCE}}$ (Harley 2005: 49-50), called activities and semelfactives by Harley respectively.

(9) Sue hopped

(10) Sue danced \#for five minutes/\#in five minutes.

for five minutes/\#in five minutes.

Harley argues that the crucial difference between Things and Events is that bounded Event Roots do not result in an accomplishment interpretation of the $\mathrm{vP}$ that they occur in. Rather, these roots name an event that occurs at a point in time, which

\footnotetext{
${ }^{4}$ See also Levinson $(2007,2010)$ on the ontology of roots, and Acquaviva (2009).
} 
makes them point-like as opposed to bounded Things that take up a certain amount of space or evolves in time (see also Pustejovsky 1991, Jackendoff 1991).

Lastly, Stative roots are roots like $\sqrt{ }$ FLAT and $\sqrt{ }$ ROUGH, exemplified in (11)(12) (Harley 2005: 55), which have a semantic structure that can be characterized as 'CAUSE+STAte'.

(11) Jill flattened the metal (\#of bumps).

(12) Jill roughened the surface (\#of scratches).

These change of state predicates are not happy to take a complement, but there are other predicates which allow them, as illustrated in (13)-(14) (Harley 2005: 54).

(13) Jill cleared the table (of dishes).

(14) Jill emptied the box (of marbles).

Change of states are different from Things and Events since for the latter two it is largely the root itself that determines the Aktionsart properties. For change of state predicates, the verb's Aktionsart is largely determined by the extent to which some state is true of a given verb's Theme.

Another proposal can be found in Alexiadou, Anagnostopoulou and Schäfer (2006), and Harley \& Noyer (2000), building on Levin and Rappaport Hovav (1995), where they argue that roots fall into the following four classes.

(15) a. Vagentive (murder, assassinate)

b. Vinternally caused (blossom, wilt) 


\section{c. Vexternally caused (destroy, kill) \\ d. $\quad \sqrt{\text { cause unspecified (break, open) }}$}

From a different perspective, Rappaport, Hovav and Levin (2010) argue that roots belong to two ontological classes, namely manner and result, which influence among other things the range of argument alternations verbs built on the basis of each root can appear in. We will not discuss the arguments in favor of this decomposition of root meaning, suffice it to point out that there are various suggestions in the literature emphasizing that roots have substantial meaning independent of their configuration. ${ }^{5}$

The next question to be addressed is whether or not all languages behave like English; that is, whether there is variation among languages in terms of how much meaning a given root does or does not have. In the remainder of this article, we will address this question, proposing a typology of languages illustrated mainly by comparing English, Greek and Hebrew. We will start with a general discussion of Hebrew and English.

\section{$3 \quad$ Hebrew and English}

Arad $(2003,2005)$ was the first to highlight the differences between languages when it comes to roots. She makes the claim that there is a distinction between two types of languages: A Hebrew-type, where a single root may form multiple nouns and verbs, and an English-type, where each root is normally assigned one interpretation in a nominal or verbal environment (Arad 2003: 740). Arad claims that Hebrew instantiates a phenomenon labeled multiple contextualized meaning, which involves a

\footnotetext{
${ }^{5}$ There is also other work denying that roots have an ontological classification, viz. Borer (2005a, b, 2013), Acquaviva (2014), and Acedo-Matellán and Mateu (2014).
} 
root acquiring multiple meanings depending on its environment. Considering the verbal system, about fifteen percent of the Hebrew roots display multiple contextualized meanings. About twenty-seven percent of the roots do not alternate (Arad and Shlonsky 2003). In the following examples taken from Arad (2003: 743744), roots displaying multiple meanings are illustrated.

(16) $\sqrt{\text { šmn }}$
a. $\quad \mathrm{CeCeC}(\mathrm{n})$
semen
'oil, grease'
b. $\quad$ CaCCeCet (n)
šamenet
'cream'
c. $\quad \mathrm{CuCaC}(\mathrm{n})$
šuman
'fat'
d. $\quad \mathrm{CaCeC}(\operatorname{adj}$.
šamen
'fat'
e. $\operatorname{hiCCiC}(v)$
hišmin
'grow fat/fatten'
f. $\quad \mathrm{CiCCeC}(\mathrm{n})$
šimen
'grease'

(17) $\sqrt{ } \mathrm{bxn}$
a. $\mathrm{CaCaC}(\mathrm{v})$
baxan
'test, examine'
b. hiCCiC (v)
hivxin
'discern'
c. $\operatorname{miCCaC}(n)$
mivxan
'an exam'
d. $\operatorname{CoCaC}(\mathrm{n})$
boxan
'a quiz'
e. $\quad \mathrm{maCCeCa}(\mathrm{n})$
mavxena
'a test-tube'
f. $\quad \mathrm{aCCaCa}(\mathrm{n})$
avxana
'a diagnosis'

(18) $\sqrt{ } \mathrm{xšb}$
a. $\mathrm{CaCaC}(\mathrm{v})$
$x a s ̌ a v$
'think'
b. $\quad \mathrm{CiCCeC}(\mathrm{v})$
xišev
'calculate' 


$\begin{array}{llll}\text { c. } & \operatorname{hiCCiC}(\mathrm{v}) & \text { hexšiv } & \text { 'consider' } \\ \text { d. } & \operatorname{hitCaCCeC}(\mathrm{v}) & \text { hitxašev } & \text { 'be considerate' } \\ \text { e. } & \operatorname{maCCeC}(\mathrm{n}) & \max 5 \check{s} e v & \text { 'a computer/calculator' } \\ \text { f. } & \operatorname{maCCaCa}(\mathrm{n}) & \max \check{s} a v a & \text { 'a thought' } \\ \text { g. } & \operatorname{CCiCut}(\mathrm{n}) & \text { xašivut } & \text { 'importance' } \\ \text { h. } & \operatorname{CiCCon}(\mathrm{n}) & \text { xešbon } & \text { 'arithmetic/bill' } \\ \text { i. } & \operatorname{taCCiC}(\mathrm{n}) & \text { taxšiv } & \text { 'calculus' }\end{array}$

(19) $\sqrt{ }$ qlt
a. $\mathrm{CaCaC}(\mathrm{v})$
qalat
'absorb, receive'
b. $\operatorname{hiCCiC}(\mathrm{v})$
hiqlit
'record'
c. $\operatorname{miCCac}(\mathrm{n})$
miqlat
'a shelter'
d. $\operatorname{maCCeC}(n)$
maqlet
'a receiver'
e. $\operatorname{taCCiC}(n)$
taqlit
'a record'
f. $\quad$ CaCCeCet (n)
qaletet
'a cassette'
g. $\mathrm{CeCeC}(\mathrm{n})$
qelet
'input'

Arad emphasizes that despite the apparent differences within each group, they all share the core root. The phonological core is evident whereas the semantic core is underspecified. She argues that it is possible to extract a highly general meaning for most of the above groups. These are provided in (20).
(20)
a. ل ل
b. $\sqrt{ } \mathrm{xšb} \quad$ 'mental activity'
c. $\quad \sqrt{\text { qlt }} \quad$ 'absorption, taking in' 
Despite this general meaning that can be attributed to the root, the individual meanings of the words are rather different. Which meaning is assigned to which word is, as expected, arbitrary: There is nothing that forces a specific root in a given environment to receive the interpretation it does.

English is different from Hebrew. In this language, roots seem to have some substantial meaning which is rather independent of the syntactic configuration in which they occur (Harley 2005, Alexiadou, Anagnostopoulou and Schäfer 2006, and Levin and Rappaport Hovav 2008). ${ }^{6}$ One simple illustration of that is the contrast between (21) and (22).

(21) a. VCREAM

b. $\quad \sqrt{ }$ FAT
a. $\quad \mathrm{CaCCeCet}(\mathrm{n})$
šamenet
'cream'
b. $\quad \mathrm{CuCaC}(\mathrm{n})$
šuman
'fat'

English employs two morphologically unrelated roots whereas Hebrew utilizes the

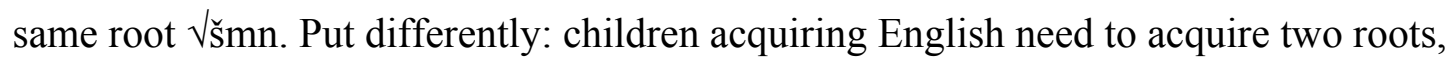
children acquiring Hebrew need to acquire two different interpretations associated with the same root (Arad 2003: 743).

However, roots in English appear in different guises, and there are roots that can appear in different syntactic contexts. Consider the root $\sqrt{ }$ RUN. This root can encode a wide range of meanings, illustrated in (23). ${ }^{7}$

\footnotetext{
${ }^{6}$ Latinate bound roots such as $\sqrt{ }$ FER, $\sqrt{ }$ CEIVE are exceptional, cf. Arad (2003: 743).

${ }^{7}$ We are grateful to an anonymous reviewer for highlighting this issue.
} 
(23) a. run (n) 'a turn/try', as in Take another run at it

b. $\quad \operatorname{run}(\mathrm{n})$ 'a path for animals to use', as in dog run

c. run (n) as in He has the run of the whole house

d. runaway $(\mathrm{n})$ 'someone who escaped'

e. the runs (n) 'diarrhea'

f. rundown (n) 'synposis of information', as in Give me the rundown on Smith

g. running (v) 'working', as in My refrigerator is not running

h. $\quad \operatorname{run}(\mathrm{v})$ 'try to get elected', as in I'll run for president/sentator ...

i. $\quad \operatorname{run}(\mathrm{v})$ 'control, lead', as in She runs the psychology lab

j. $\quad$ overrun (v) 'dominate, take over'

k. run into/across $(\mathrm{v})$ 'encounter'

1. run me into the store (v) as in drive me to the store

m. run (along) (v) 'leave', as in I have to run

n. run down (v) 'strike with a car'

o. run out 'come to have no more', as in I have to run

p. run up 'make something bigger', as in Run up the bill

q. runny, as in a runny nose

These examples could be taken to show that the manner root $\sqrt{ }$ RUN has some underspecification, which is fixed by its local context, be it a preposition, a complement, or a prefix; crucially assuming that it is the same root $\sqrt{R U N}$ in all the instances in (23). However, many of these instances are arguably idiomatic/fixed expressions, which means that they are not examples of productive uses of $\sqrt{ }$ RUN. Rather, the root is stored as part of a larger expression and acquires its meaning based 
on that expression. If so, then the examples in (23) do not demonstrate that roots in English are very flexible, contrary to Hebrew.

There is a range of other imaginable meanings that the root $\sqrt{ } \mathrm{RUN}$ cannot encode. The examples in (24) show some of the meanings that the root cannot encode all by itself.

$\sqrt{ }$ RUN
a. $\quad$ *to run very fast $(\mathrm{v})$
b. *a walk (n)
c. $\quad *$ a runny nose $(\mathrm{a})$
d. *a run happening in intervals

Although a lot of English roots can appear both as nouns and verbs, they usually have pretty similar meanings as either nouns or verbs. Furthermore, unlike Hebrew, English does not have a rich functional vocabulary that is responsible for fixing the interpretation of roots. Arad takes the functional morphology to be crucial, and even for someone insisting that data such as (23) demonstrate an incredible flexibility of English roots; this flexibility is not determined or fixed by functional morphology.

To summarize, we have two languages on each side of the scale: Hebrew with little root independent meaning and several functional morphemes, and English with root independent meaning and few functional morphemes. One question that we have not yet answered is whether we are dealing with a binary opposition or a scale along which languages can be placed? We turn to that question in the next section.

\section{Causativization in English}


In this section, we will consider data from the history of English that will demonstrate that English used to be different in terms of functional vocabulary that contribute to fixing the meaning of a given root.

Van Gelderen (2011) documents a series of verbal valency changes in the history of the English language. She notes that there is a causativizing affix $-j$ in early Germanic, which becomes $-i$ in Old English. Lass (1994: 166) argues that by Old English, only a small group of verbs shows the presence of this $-i$ causativizer. Thus it does not appear to be very productive. The example in (25) is analyzed as in (26) in van Gelderen (2011: 124).

(25) Ac utan glad-i-an georne God ælmihtigne.

but let.we glad-caus-inf eargerly God almighty

But let us make God the almighty glad eagerly.' (Wulfstan Homilies)

(26)

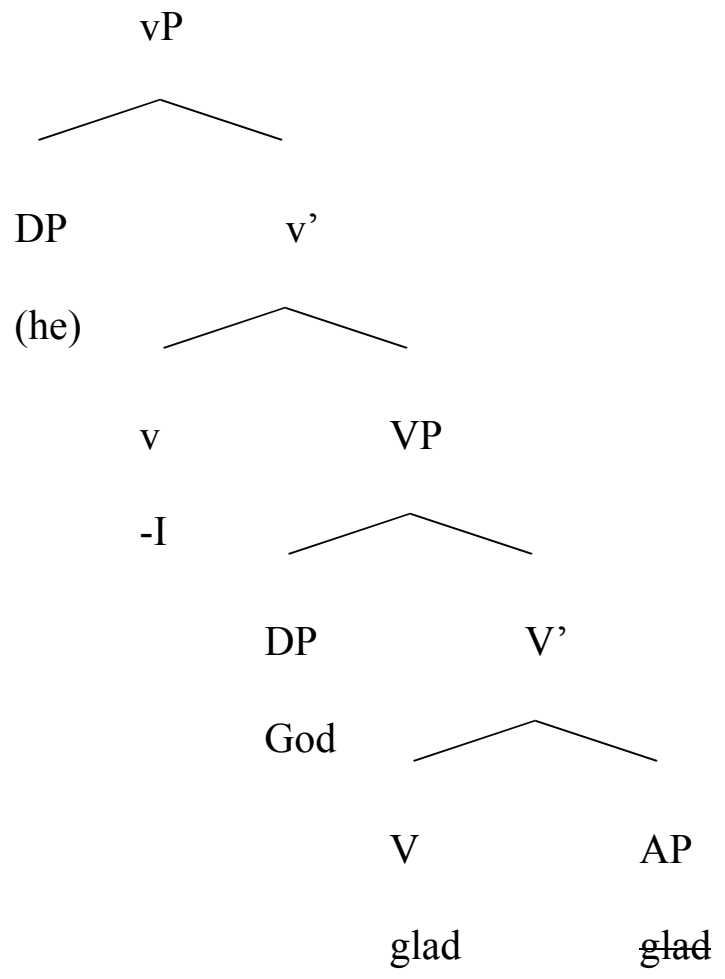


In the Middle English period, a new causativizer is introduced, namely -en. This causativizer is very productive. Examples are provided in (27) from van Gelderen (2011: 125).

(27) awaken, blacken, brighten, broaden, cheapen, coarsen, dampen, darken, deafen, deepen, fasten, fatten, flatten, freshen, frighten, gladden, harden, hasten, hearten, heighten, lengthen, lessen, lighten, loosen, madden, moisten, neaten, quicken, quieten, redden, ripen, roughen, sadden, sharpen, shorten, sicken, slacken, smarten, soften, stiffen, straighten, strengthen, sweeten, tauten, tighten, toughen, waken, weaken, whiten, widen, worsen.

Van Gelderen also points out that there are three other causative suffixes: -ize, -(i)fy, ate (e.g., advertize, abdicate, beautify). These are not fully productive and were borrowed from Greek and Latin. She argues that in Modern English, -en and zero derivations derive a causative from an unaccusative. She analyzes -en as an instance (a 'flavor', cf. Folli and Harley 2005, 2007, Embick 2009) of little v, though with a clear causative semantics (Harley 2009).

We argue that this causative semantics is not encoded in the head per se, but rather emerges as a property of the entire syntactic configuration (Hale and Keyser 1993, Higginbotham 2000, Marantz 2006, Ramchand 2008, this volume, Schäfer 2012). The other 'causative' suffixes are pure verbalizers, realizing little v. The main argument for the differentiation among the suffixes is that the non-en suffixes are not productive and do not provide real causative semantics.

The history of causativization in English demonstrates that little v can be morphologically realized even in English, and that English at earlier stages looked a 
bit more like Hebrew since it had more visible morphological realizations of syntactic heads. The major change, according to van Gelderen (2011: 138), is related to "a discontinuation of marking causatives and transitives morphologically". This increased morphological opacity can be viewed as a key ingredient in understanding the development of English and also the difference between English and Hebrew, cf. section 3 .

\section{$5 \quad$ Roots in Greek}

In this section, we will look at a language that seems to be placed somewhere in the middle between English and Hebrew, namely Greek. Before we can turn to the main point, which is that Greek has a set of underspecified roots which makes it look more like Hebrew, some background on the relevant data are in order.

In Greek, there are two participles that attach to verbs:-tos and -menos.

Consider the following examples from Alexiadou and Anagnostopoulou (2008).

$\begin{array}{ccccc}\text { (28) } & \text { vraz-o } & \text { vras-men-os } & \text { vras-t-os } & \text { 'boiled' } \\ \text { b. } & \text { psin-o } & \text { psi-men-os } & \text { psi-t-os } & \text { 'grilled' } \\ \text { c. } & \text { zograf- } & \text { zografis-men-os } & \text { zografis-t-os } & \text { 'painted' } \\ \text { d. } & \text { anig-o } & \text { anig-men-os } & \text { anix-t-os } & \text { 'opened', 'open' }\end{array}$

These two participles function on a par with adjectives, which is to say that they appear in attributive and predicative positions. The following examples illustrate this.
(29) a. to
anih- $t$-o
parathiro
the-neut.sg.nom
open- $t$-neut.sg.nom window 
'the open window'

b. to

anig-men-o

parathiro

the-neut.sg.nom

open-men-neut.sg.nom

window

'the opened window'

(30)

a. to parathiro ine anih- $t$-o

the window is

open-t-neut.sg.nom

'the window is open'

b. to parathiro ine anig-men-o

the window is open-men-neut.sg.nom

'the window is opened'

Anagnostopoulou (2003) and Alexiadou and Anagnostopoulou (2008) argue that -tos participles lack event implications, whereas -menos participles are different: these denote states resulting from prior events. In the example in (31), (31a) means that the potatoes are fried as a result of a frying event, whereas (31b) means that the potatoes had been cooked in a particular way ("characteristic state" interpretation) (Anagnostopoulou and Samioti 2014: 88).

(31) a. I patates ine tiganis-men-es

The potatoes are fry-men-fem.pl.nom

'The potatoes are fried'

b. I patates ine tigani-t-es

The potatoes are fry-t-fem.pl.nom

'The potatoes are fried' 
Anagnostopoulou and Samioti furthermore show that this difference in event implication is related to a number of syntactic differences. - menos participles can be modified by manner adverbs (32a), can license by-phrases and instrument PPs (33a), while -tos adjectives cannot (32b, 33b).

a. Afto to vivlio ine kala gra-men-o
This the book is well written
'This book is well-written'
b. *Afto to kimeno ine kala grap-t-o
This the text $\quad$ is well written

a. O tixos ine xtis-men-os me mistri/ apo ton ergati The wall is built with trowel/ by the worker 'The wall is built with a trowel/ by the worker'

$\begin{array}{lll}\text { b. } \quad \text { O tixos ine } & \text { xtis- } t \text {-os me mistri/ apo ton ergati } \\ \text { The wall is } & \text { built } & \text { with trowel/ by the worker }\end{array}$

See Anagnostopoulou and Samioti (2014) for a more complete discussion of further syntactic differences.

In terms of the syntactic analysis, Alexiadou and Anagnostopoulou (2008) suggest that -tos participles attach to the root below the category-defining head. menos (target state) participles are different: these denote states resulting from prior events. They attach above the category-defining head $v$, which is taken to be the eventivizing head. This can be illustrated in (34) and (35). 
(34)

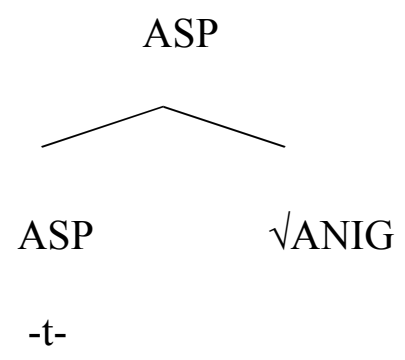

(35)

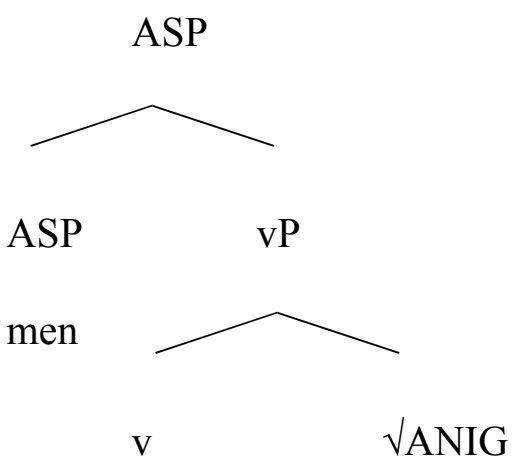

Thus, the attachment of the two participles is different, yielding different interpretations. There is also a third type of participle in Greek: -menos resultant state participles that include both implication of an event and agentivity. ${ }^{8}$ For this type, the participle attaches to Voice.

Now we will return to looking at how the above data serve as a background to understanding the relevance of Greek for the typology of root categorization that we are seeking to develop in this paper. Anagnostopoulou and Samioti (2014: 81) identify the Marantz/Arad Hypothesis (Marantz 2001, 2007, Arad 2003, 2005) (36) as a condition on the emergence of idiosyncratic meanings.

\section{(36) The Marantz/Arad Hypothesis}

\footnotetext{
${ }^{8}$ See Parsons (1990: 234-235), Kratzer (2001) and Anagnostopoulou (2003) on the difference between target state participles and resultant state participles.
} 
Roots are assigned an interpretation in the context of the first category assigning head/phase head merged with them, which is then fixed throughout the derivation.

In the present context, this means that-menos participles are expected to have a predictable meaning whereas - tos participles will be highly idiosyncratic (cf. Anagnostopoulou 2003, Alexiadou and Anagnostopoulou 2008).

Anagnostopoulou and Samioti (2014) show that this picture is simplified in the sense that -tos participles often behave as if they were attached outside the category-defining head. This is relevant, because their analysis shows dissociation among roots: Some roots have substantial meaning; others have a meaning that depends on the syntactic environment.

Greek has suffixes that serve to verbalize a root (Giannakidou and Merchant 1999, Alexiadou 2001, 2009, Ralli 2001, Panagiotidis et al this volume).
a. aspr-iz-o, kathar-iz-o
b. pag-on-o ler-on-o
whiten cleaned
freeze
dirty
c. diaplat-en-o, arost-en-o
d. sten-ev-o berd-ev-o
widen, become sick
tighten
confuse
e. diav-az-o, mir-az-o
f. pul-a-o xal-a-o
read
split, share
sell
destroy

(Anagnostopoulou and Samioti 2014: 96) 
The -menos participle can attach outside of the verbalizing suffix.

$\begin{array}{lll}\text { (39) } & \text { aspr- } i z \text {-menos } & \text { kathar- } i z \text {-menos } \\ & \text { whitened } & \text { cleaned } \\ \text { b. } & \text { pag-o-menos } & \text { ler- } o \text {-menos } \\ & \text { frozen } & \text { dirtied } \\ \text { c. } & \text { diaplat- } i \text {-menos } & \text { arost- } i \text {-menos } \\ & \text { widened } & \text { sickened }\end{array}$

Typically, root verbalizers cannot occur together with -tos participles (Alexiadou and Anagnostopoulou 2008), which Alexiadou and Anagnostopolou (2008) take to mean that -tos attaches to the root without the presence of a verbalizing head.

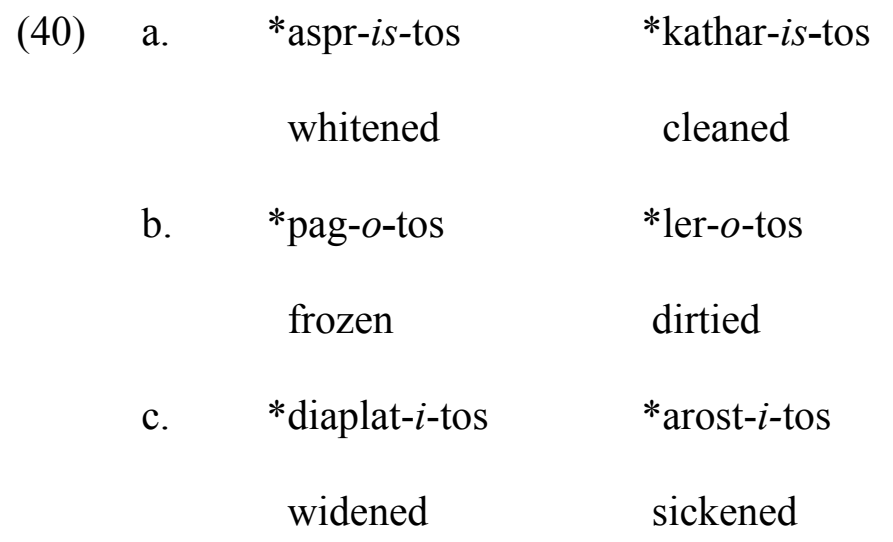

However, Anagnostopoulou and Samioti (2014: 97) show that there is a range of cases where -tos participles can occur.
(41)
a. axn-is-tos 'steaming hot'
axn-iz-o 'steam'
b. koudoun-is-tos 'ringing'
koudoun-iz-o 'ring (a bell)' 
c. vathoul-o-tos 'hollow' vathoul-on-o 'hollow out'

Importantly, these -tos participles do not have event implications (they denote characteristic states), and they do not license manner modification, agent PPs or instruments (Anagnostopoulou and Samioti 2014: 97).

a. *To fagito ine kala/ prosektika magir-ef- $t$-o The food is well/ carefully cooked

b. *To fagito ine magir-ef- $t$-o apo tin Maria The food is cooked by the Mary

c. ${ }^{*}$ Ta fita ine fit-ef- $t$-a me diaforetika ergalia The plants are planted with different instruments

Anagnostopoulou and Samioti (2014) take these facts to show that little v, which typically introduces event interpretations (e.g., Embick 2004, Alexiadou, Anagnostopoulou and Schäfer 2006, Marantz 2001, 2007, Harley 2012) has to be dissociated from verbalizers that are realized morphologically. See also Alexiadou (2009) for result nominals in Greek. We endorse this position.

Anagnostopoulou and Samioti (2014) show that roots fall into different ontological categories, impacting their syntactic realization. They follow Harley (2005) in assuming that the basic ontological types are as listed in (43).
a. events
b. things
c. states

They provide a set of generalizations (pp. 99-104): 
(44) a. -tos directly attaches to roots which can be characterized as Root event. $_{\text {. }}$

b. - $\quad$ tos does not combine with Root $t_{\text {thing. }}$ It combines with Root thing + verbalizer.

c. $\quad-$ tos does not combine with Root $_{\text {state }}+$ verbalizer because an adjective blocks the -tos form. ${ }^{9}$

d. verbalizers turn undefined roots into an event and then -tos attaches to the Root $_{\text {undefined }}+$ verbalizer. (Cf. Arad 2003, 2005)

Let us consider the last generalization more carefully. ${ }^{10}$ The roots to which -tos attaches are roots with no clear meaning, hence the name: Root ${ }_{\text {undefined. }}$ There are two ways in which the meaning is undefined: i) it is impossible to assign an exact meaning to the root, and ii) no corresponding noun or verb of the form Root undefined + inflection exists. Anagnostopoulou and Samioti distinguish between two subclasses.

The first class consists of undefined roots which represent movements, sounds or shapes, and they are often formed by reduplication. They require a verbalizer in order to become verbs, and then they become adjectives, as in (45), or nouns (Anagnostopoulou and Samioti 2014: 102).
a. kakar-is-tos
'cackling'
b. tsitsir-is-tos
'sizzling / frizzling'
c. trekl-is-tos
'staggering'

\footnotetext{
${ }^{9}$ A relevant example is the following: aspr-os/i/o 'white' and aspr-iz-o 'whiten'. It is possible to say aspr-iz-men-os, but not *aspr-is-tos (cf. 40a). See also Alexiadou and Anagnostopoulou (2008).

${ }^{10}$ See Anagnostopoulou and Samioti for elaborate discussion of the other generalizations.
} 


$\begin{array}{lll}\text { d. } & \text { tourtour-is-tos } & \text { 'shivering / shuddering' } \\ \text { e. } & \text { gourl-o-tos } & \text { 'goggling' } \\ \text { f. } & \text { koxl-as-tos } & \text { 'bubbling' } \\ \text { g. } & \text { xarxal-ef-tos } & \text { 'rummaging' } \\ \text { h. } & \text { paspat-ef-tos } & \text { 'fiddling' }\end{array}$

The second class is made up of roots "which seem completely and totally undefined before a verbalizer attaches to them", making them eventive (Anagnostopoulou and Samioti 2014: 102).

$\begin{array}{lll}\text { a. } & \text { kt-is-tos } & \text { 'built' } \\ \text { b. } & \text { sk-is-tos } & \text { 'slit' } \\ \text { c. } & \text { str-o-tos } & \text { 'smooth, regular' } \\ \text { d. } & \text { lig-is-tos } & \text { 'bent' } \\ \text { e. } & \text { sik-o-tos } & \text { 'raised' }\end{array}$

These roots are like Hebrew roots in that they cannot occur without the functional morphology. They also fall together with words based on Proto-Indoeuropean roots where the prefixes are drawn from the Ancient Greek prepositional inventory. These prefixes fix the meaning of these unspecified roots. ${ }^{11}$ See Alexiadou and Anagnostopoulou $(2011,2013)$ for further discussion.

\footnotetext{
${ }^{11}$ Anagnostopoulou and Samioti also raise the question of why categorizers serve as contexts for meaning assignment to unspecified roots. They argue that roots have to be classified in terms of Harley's (2005) basic ontology. If not, as in the Greek examples just discussed, a categorizer is needed in order to classify the roots. Whatever meaning the root then acquires, it remains throughout the derivation.
} 
Anagnostopoulou and Samioti conclude that Greek is what Arad (2003) calls an English-type language. However, we are inclined to draw a somewhat different conclusion: Greek seems to be somewhere in between Hebrew and English. There are more contexts in Greek in which unspecified roots have their meanings productively determined by prefixes than in English. Again this is an important point about the role of functional morphology in differentiating languages when it comes to determining meaning.

\section{Roots across languages: a typology}

We argue that it is possible to devise a typology of roots and functional morphemes where languages are sorted on a scale. Based on the case studies reported in this paper, we can devise the typology in (47).

\section{A scale from 'empty' roots to 'contentful' roots}

Hebrew $>$ Greek $>$ Old English $>\quad$ English

In Hebrew, functional morphemes and especially verbalizers are crucial in determining the interpretation of a root. In contemporary English, this is not the case, and the interpretation of the root is to a greater extent determined by the meaning of the root itself: he functional morphemes play a minor, if any, role in determining the meaning of English roots. Roots in Hebrew are 'empty' in the sense that they have highly general and underspecified meanings, whereas although some roots in English are underspecified, their meanings are to a greater extent determined by the semantic content of the root itself. 
It is important that the typology is scalar. We do not think that it is possible to neatly define the typology into discrete steps or categories in which all languages can be sorted. For that reason, the typology does not tell the researcher how to position languages with respect to each other on the scale. In order to do that, more quantitative measures of the number of underspecified roots vs. the number of specified roots would have to be developed, which could easily result in rather arbitrary distinctions. Rather, we are dealing with gradient transitions between languages. A language like Hebrew seems to mark one end of the scale, whereas English seems to mark the other. There may also be yet more 'extreme' languages that we have not come across. As it stands, such languages would just move the endpoints of the scale and therefore not threaten our proposal.

An alternative and quite different perspective is the following three-way typology of root meanings. ${ }^{12}$

$\begin{array}{lll}\text { root }> & \text { stem }> & \text { word } \\ \text { Hebrew } & \text { Greek } & \text { English }\end{array}$

This typology is more restricted in that it predicts three classes of languages: i) languages where the root is rather contentless and the word serves as the basic unit, ii) languages where the root strongly influences the meaning of a word, iii) languages in between where the stem is the basic unit of meaning. Here we take a stem to be the node directly dominating the categorizing head and the root, so a stem is the minimal unit comprising a root and its categorizer. The typology in (48) has the advantage of

\footnotetext{
${ }^{12}$ We are grateful to Elena Anagnostopoulou (p.c.) for this idea.
} 
connecting meaning and morphology, although it also predicts three discrete classes of languages.

We have put forth two different alternative analyses: Languages can either be placed on a continuous scale in terms of how much semantics is encoded in the root, or all languages can be divided into one of three discrete classes according to whether the basic unit is a root, a stem, or a word. Larger typological investigations would be required in order to choose between these two alternatives.

Anagnostopoulou and Samioti (2014) provide a series of examples that suggest that in Greek categorizing affixes take stems as their input. In their discussion of examples such as [(49)], they point out that "First, the absence of $-n-$ in the verbal adjectives as in [(49a)] could be viewed as evidence that -tos directly attaches to the root and not to the verb, if it can be ensured that the reason for the absence of $-n-$ is not morpho-phonological. Second, in [(49c, e, g)] -tos attaches to the perfective stem (marked by stem allomorphy in [49c, e] and by the presence of $-s-$ in $[49 \mathrm{~g}]$ ), a fact that could, in principle, receive either a semantic or a phonological explanation" (p. 99).

$\begin{array}{lllll}\text { a. } & \text { ftiax-n-o } & \text { 'make' } & \text { ftiax-tos } & \text { 'made' } \\ \text { b. } & \text { lin-o } & \text { 'loosen' } & \text { li-tos } & \text { 'loose' } \\ \text { c. } & \text { per-n-o } & \text { 'take' } & \text { par-tos } & \text { 'taken' } \\ \text { d. } & \mathbf{k l e v - o} & \text { 'steal' } & \text { klef-tos } & \text { 'stolen' } \\ \text { e. } & \text { din-o } & \text { 'give' } & \text { do-tos } & \text { 'given' } \\ \text { f. } & \text { plek-o } & \text { 'knit' } & \text { plek-tos } & \text { 'knitten' } \\ \text { g. } & \text { klin-o } & \text { 'close' } & \text { klis-tos } & \text { 'closed' }\end{array}$


Our proposal suggests that little v plays different roles in different languages: in Hebrew it is crucial for determining the interpretation of roots and thereby words, whereas in English it categorizes roots and also determines aspects of meaning (see e.g., Marantz 2013 and the discussion in section 5). In English, and partly in Greek, it is Voice that is the most important head for determining (idiomatic) interpretation (see Anagnostopoulou and Samioti 2013, 2014 and references therein for much discussion). Therefore, we argue that little $\mathrm{v}$ is always a verbalizer in all languages, though it can also take on additional roles, such as in Hebrew where it is strongly linked to determining the interpretation of roots by way of functional morphology.

We mentioned above that there is evidence from the literature that $\mathrm{v}$ can be of two types even in languages such as English and Greek, and discussed the distinction between a $v$ head in the context of causative semantics, and pure verbalizers. Clearly, this departs from the view of $\mathrm{v}$ as being the head introducing the external argument, in e.g., Chomsky (1995), Embick (2004), Collins (2005), Folli and Harley (2008), Harley (2013), Merchant (2013). External arguments are introduced by Voice, cf. Kratzer (1996), Alexiadou, Anagnostopoulou and Schäfer (2006). See also Harley (this volume), Schäfer (this volume), and Sundaresan and McFadden (this volume) for discussion.

One remaining question is whether we need to encode semantics on little v heads. Ramchand (2008, this volume) and Schäfer (2012), among others, have shown that the grammar does not make reference to annotated $v$ heads, or flavors of $v$. In line with their proposals, we maintain that all $\mathrm{v}$ heads are verbalizers. The semantics of the constructions result from the combination of $\mathrm{v}$ heads and different types of roots (unlike, e.g., Pylkkänen 2008; see also Harley this volume for discussion). In particular, the combination of $\mathrm{v}$ with a particular type of root (result) or a small clause 
gives rise to causative semantics. For instance, as we saw above, most -en verbs in English are built on the basis of roots that bring about a state/result.

\section{Conclusions}

In this paper, we have discussed the question of what the division of labor is between the root and the functional morphemes categorizing the root across a small set of languages. We argue that it is possible to devise a typology of roots and functional morphemes where languages are sorted on a scale. Given the languages we have looked at here, the scale ranges from Hebrew on the one hand to English on the other hand. In Hebrew, functional morphemes and especially verbalizers are crucial in determining the interpretation of a given root and thus a given word. In contemporary English, this is not the case, and the interpretation of the root and thereby the word is to a greater extent determined by the meaning of the root itself. Greek is argued to fall in between English and Hebrew on the scale.

For English, Greek, and Hebrew, the root is a crucial building block. Languages are partitioned on a scale depending on exactly what the semantic properties of the roots are. The fact that roots play this important role offers indirect support in favor of the existence of roots, since if they did not exist, it would be much harder to understand the ways in which the three languages discussed differ.

We have also argued that little v works differently in English, Greek, and Hebrew. In Greek, it introduces functional morphology that plays a crucial role when it comes to determining the meaning of a root in the context of a word. In English, it is a verbalizer, although it may also be linked to fixing the domain for allosemy (Marantz 2013). Given that little v plays these roles, it cannot introduce an external 
argument; a separate functional projection above little $\mathrm{v}$ is needed to do that, viz. Voice.

\section{References}

Acedo-Matellán, Víctor and Jaume Mateu (2014). 'From syntax to roots: A syntactic approach to root interpretation', in Artemis Alexiadou, Hagit Borer and Florian Schäfer (eds.), The Syntax of Roots and the Roots of Syntax. Oxford: Oxford University Press, 14-32.

Ackema, Peter and Ad Neeleman (2004). Beyond Morphology. Oxford: Oxford University Press.

Acquaviva, Paolo (2009). 'Roots and lexicality in Distributed Morphology', in Alexandra Galani, Daniel Redinger and Norman Yeo (eds.), York-Essex Morphology Meeting 5: Special Issue of York Working Papers in Linguistics. York: University of York, Department of Language and Linguistic Science, 121.

Acquaviva, Paolo (2014). 'The roots of nominality, the nominality of roots', in Artemis Alexiadou, Hagit Borer and Florian Schäfer, The Syntax of Roots and the Roots of Syntax. Oxford: Oxford University Press, 33-56.

Åfarli, Tor A (2007). 'Do verbs have argument structure?', in Eric Reuland, Tanmoy Bhattacharya and Giorgos Spathas, Argument Structure. Amsterdam: John Benjamins, 1-16.

Alexiadou. Artemis (2001). Functional Structure in Nominals. Amsterdam: John Benjamins. 
Alexiadou, Artemis (2009). 'On the role of syntactic locality in morphological processes: the case of (Greek) nominals', in Anastasia Giannakidou and Monika Rathert (eds.), Quantification, Definiteness, and Nominalization.. Oxford: Oxford University Press, 253-280.

Alexiadou, Artemis and Elena Anagnostopoulou (2008). 'Structuring Participles', in Charles B. Chang and Hannah J. Haynie (eds.), Proceedings of the 26th West Coast Conference on Formal Linguistics. Somerville, MA: Cascadilla Proceedings Project, 33-41

Alexiadou, Artemis and Elena Anagnostopoulou (2011). 'Decomposing the Greek verb. The view from the clear-alternation', paper presented at Approaches to the Lexicon (Roots II), The Hebrew University of Jerusalem, June 13-16.

Alexiadou, Artemis and Elena Anagnostopoulou (2013). 'Manner vs. Result Complementarity in Verbal Alternations: A View from the Clear-Alternation', in Stefan Keine and Shayne Sloggett (eds.), Proceedings of the Forty-Second Annual Meeting of the North East Linguistic Society. University of Massachusetts, Amherst: GSLA, 39-52.

Alexiadou, Artemis, Elena Anagnostopoulou and Florian Schäfer (2006). 'The Properties of Anticausatives Cross-linguistically', in Mara Frascarelli (ed.) Phases of Interpretation. Berlin: Mouton de Gruyter, 187-212.

Alexiadou, Artemis, Elena Anagnostopoulou and Florian Schäfer (2015). External Arguments in Transitivity Alternations. A Layering Approach. Oxford: Oxford University Press.

Anagnostopoulou, Elena (2003). 'Participles and Voice', in Artemis Alexiadou, Monika Rathert and Arnim von Stechow (eds.), Perfect Explorations,.Berlin: Mouton de Gruyter, 1-36.. 
Anagnostopoulou, Elena and Yota Samioti (2014). 'Domains within Words and their meanings: a case study', in Artemis Alexiadou, Hagit Borer and Florian Schäfer (eds.), The Syntax of Roots and the Roots of Syntax. Oxford: Oxford University Press, 81-111.

Anderson, Stephen (1982). 'Where's Morphology?', Linguistic Inquiry 13: 571-612. Anderson, Stephen (1992). A-morphous morphology. Cambridge: Cambridge University Press.

Arad, Maya (2003). 'Locality constraints on the interpretation of roots: The case of Hebrew denominal verbs', Natural Language and Linguistic Theory 21: 737778.

Arad, Maya (2005). Roots and patterns: Hebrew morphosyntax. Dordrecht: Springer. Arad, Maya and Ur Shlonsky (2003). 'Roots and Patterns: Hebrew Morpho-Syntax', unpublished ms., University of Geneva.

Aronoff, Mark (1976). Word formation in generative grammar. Cambridge, MA: MIT Press.

Baker, Mark C. (1985). 'The Mirror Principle and Morphosyntactic Explanation', Linguistic Inquiry 16: 373-416.

Berman, Ruth (1978). Modern Hebrew Structure. Tel Aviv: Tel Aviv University Press. Borer, Hagit (2005a). Structuring Sense: In Name Only. Oxford: Oxford University Press.

Borer, Hagit (2005b). Structuring Sense: The Normal Course of Events. Oxford: Oxford University Press.

Borer, Hagit (2013). Structuring Sense: Taking Form. Oxford: Oxford University Press.

Caha, Pavel (2009). The nanosyntax of case. Doctoral dissertation, University of 
Tromsø.

Carstairs-McCarthy, Andrew (1992). Contemporary Morphology. London:

Routledge.

Chomsky, Noam (1957). Syntactic Structures. The Hague: Mouton.

Chomsky, Noam (1970). 'Remarks on nominalization', in Roderick A. Jacobs and

Peter S. Rosenbaum (eds.), Readings in English transformational grammar. Waltham, MA: Ginn, 184-221.

Chomsky, Noam (1995). The Minimalist Program. Cambridge, MA: MIT Press.

Collins, Chris (2005). 'A smuggling approach to the passive in English', Syntax 8: 81120.

Di Sciullo, Anna Marie (2005). Asymmetry in Morphology. Cambridge, MA: MIT Press.

Doron, Edith (1999). 'The Semantics of Semitic Templates', unpublished manuscript, Hebrew University, Jerusalem.

Embick, David (2004). 'On the structure of resultative participles in English', Linguistic Inquiry 35: 355-392.

Embick, David (2009). 'Roots, States, and Stative Passives', paper presented at the Roots workshop, University of Stuttgart, June.

Embick, David (2010). Localism vs. Globalism in Morphology and Phonology. Cambridge, MA: MIT Press.

Embick, David and Alec Marantz (2008). 'Architecture and Blocking', Linguistic Inquiry 29: 1-53.

Folli, Raffaella and Heidi Harley (2005). 'Flavors of v: Consuming results in Italian and English', in Paula Kempchinsky and Roumyana Slabakova (eds.), Aspectual inquiries. Dordrecht: Springer, 95-120. 
Folli, Raffaella and Heidi Harley (2007). 'Causation, obligation, and argument structure: On the nature of little v', Linguistic Inquiry 38: 197-238.

Folli, Raffaella and Heidi Harley (2008). 'Teleology and Animacy in External Arguments', Lingua 118: 190-202.

van Gelderen, Elly (2011). 'Valency changes in the history of English', Journal of Historical Linguistics 1: 106-143.

Giannakidou, Anastasia and Jason Merchant (1999). 'Why Giannis can't scrub his plate clean: On the absence of resultative secondary predication in Greek', in Amalia Mozer (ed.), Greek Linguistics' 97: Proceedings of the $3^{\text {rd }}$ International Conference on Greek Linguistics. Athens: Ellinika Grammata, 93-103.

Hale, Kenneth and Samuel Jay Keyser (1993). 'On argument structure and the lexical expression of syntactic relations', in Kenneth Hale and Samuel Jay Keyser (eds.), The View from Building 20. Cambridge, MA: MIT Press, 53-109.

Halle, Morris and Alec Marantz (1993). 'Distributed Morphology and the pieces of Inflection', in Kenneth Hale and Samuel Jay Keyser (eds.), The View from Building 20: Essays in Linguistics in Honor of Sylvain Bromberger. Cambridge, MA: MIT Press, 111-176.

Harley, Heidi (2005). 'How do verbs take their names? Denominal verbs, manner incorporation and the ontology of roots in English', in Nomi Erteschik-Shir and Tova Rapoport (eds,), The Syntax of Aspect. Oxford: Oxford University Press, $42-64$.

Harley, Heidi (2009). 'The morphology of nominalizations and the syntax of vP', in Anastasia Giannakidou and Monika Rathert (eds.), Quantification, Definiteness, and Nominalization. Oxford: Oxford University Press, 320-342. 
Harley, Heidi (2012). 'Lexical decomposition in modern generative grammar', in Markus Werning, Wolfram Hinzen and Edouard Machery (eds.), The Oxford Handbook of Compositionality. Oxford: Oxford University Press, 328-350. Harley. Harley (2013). 'External arguments and the Mirror Principle: On the distinctness of Voice and v', Lingua 125: 34-57.

Harley, Heidi (2014). 'On the Identity of Roots', Theoretical Linguistics 40: 225-276. Harley, Heidi and Rolf Noyer (2000). 'Licensing in the non-lexicalist lexicon', in Bert Peeters (ed.), The Lexicon/Encyclopedia Interface. Amsterdam: Elsevier, 349374.

Higginbotham, James (2000). 'Accomplishments', in Proceedings of GLOW in Asia II. Nagoya: Nanzan University, 72-82

Hippilsey, Andrew and Gregory T. Stump (eds.) (2014). Cambridge Handbook of Morphology. Cambridge: Cambridge University Press.

Jackendoff, Ray (1991). 'Parts and boundaries', Cognition 41: 9-45.

Julien, Marit (2002). Syntactic Heads and Word Formation. Oxford: Oxford University Press.

Kratzer, Angelika (1996). 'Severing the external argument from its verb', in Johan Rooryck and Laurie Zaring (eds.), Phrase structure and the lexicon. Dordrecht: Kluwer, 109-137.

Kratzer, Angelika (2001). 'Building Statives', in Proceedings of the Twenty-Sixth Annual Meeting of the Berkeley Linguistic Society: General Session and Parasession on Aspect, 385-399.

Lass, Roger (1994). Old English. Cambridge: Cambridge University Press.

Levin, Beth and Malka Rappaport Hovav (1995). Unaccusativity: At the Syntax Lexical Semantics Interface. Cambridge, MA: MIT Press. 
Levin, Beth and Malka Rappaport Hovav (2008). 'A constraint on verb meanings', paper presented at Brown University.

Levinson, Lisa (2007). The Roots of Verbs. Doctoral dissertation, New York University.

Levinson, Lisa (2010). 'Arguments for Pseduo-Resultative Predicates', Natural Language \& Linguistic Theory 28: 135-182.

Lieber. Rochelle (1992). Deconstructing Morphology. Chicago: University of Chicago Press.

Lieber, Rochelle and Pavol Stekauer (eds.) (2009). The Oxford Handbook of Compounding. Oxford: Oxford University Press.

Lohndal, Terje (2014). Phrase Structure and Argument Structure: A Case Study of the Syntax-Semantics Interface. Oxford: Oxford University Press.

Marantz, Alec (1997). 'No escape from Syntax: Don't try morphological analysis in the privacy of your own lexicon', in A. Dimitriadis, L. Siegel, C. Surek-Clark and A. Williams (eds.), University of Pennsylvania Working Papers in Linguistics. Philadelphia: University of Philadelphia, 201-225.

Marantz, Alec (2001). 'Words and Things', unpublished manuscript MIT \& NYU.

Marantz, Alec (2006). 'Morphology and grammatical architecture', class material at the EALing Fall School, Ecole Normale Superieure, Paris.

Marantz, Alec (2007). 'Phases and words', in Sook-Hee Choe (eds.), Phases in the theory of grammar. Seoul: Dong In Publisher, 191-221.

Marantz, Alec (2013). 'Locality Domains for Contextual Allomorphy across the Interfaces', in Ora Matushansky and Alec Marantz (eds.), Distributed Morphology Today: Morphemes for Morris Halle. Cambridge, MA: MIT Press, 95-116. 
Merchant, Jason (2013). 'Voice and Ellipsis', Linguistic Inquiry 44: 77-108.

Parsons, Terrence (1990). Events in the Semantics of English. Cambridge, MA: MIT Press.

Pesetsky, David.(1995). Zero Syntax. Cambridge, MA: MIT Press.

Pustejovsky, James (1991). 'The syntax of event structure', Cognition 41: 47-82.

Pylkkänen, Liina (2008). Introducing Arguments. Cambridge, MA: MIT Press.

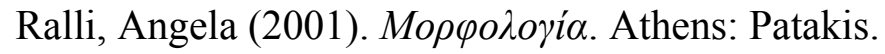

Ramchand, Gillian (2008). Verb Meaning and the Lexicon: A First Phase Syntax. Cambridge: Cambridge University Press.

Rappaport Hovav, Malka and Beth Levin (2010). 'Reflections on Manner/Result Complementarity', in Edith Doron, Malka Rappaport Hovav and Ivy Sichel (eds.), Syntax, Lexical Semantics, and Event Structure. Oxford: Oxford University Press, 21-38.

Schäfer, Florian (2012). 'Two types of external argument licensing - the case of causers', Studia Linguistica 66: 128-180.

Spencer, Andrew and Arnold M. Zwicky (eds.) (1998). The Handbook of Morphology. Malden: Blackwell.

Wunderlich. Dieter (1996). 'Minimalist morphology: the role of paradigms', in Geert Booij and Jaap van Marie (eds.), Yearbook of Morphology. Dordrecht: Kluwer, 93-114. 